\title{
Assessment on vaccine supply chain and logistics systems in the case of Ethiopian pharmaceuticals supply agency Jimma branch, Jimma south west Ethiopia
}

Tekalign Admsau Weledesenbet ( $\nabla$ tekepharm@gmail.com )

Research article

Keywords: vaccine logistics, supply chain management

Posted Date: March 2nd, 2020

DOI: https://doi.org/10.21203/rs.3.rs-15558/v1

License: (c) (i) This work is licensed under a Creative Commons Attribution 4.0 International License. Read Full License 


\section{Abstract}

Background: Immunization helps save lives, protects serious illness and is recognized as one of the most effective public health intercessions and available today. However, the success of the programs depends heavily up on the immunization supply chain management including storage, transportation and handling of vaccines in a proper manner. It was therefore important to assess the immunization supply chain and logistics practice.

Method: Institution-based cross sectional study was conducted from September to October 2019 in Ethiopian pharmaceuticals supply agency (EPSA) Jimma branch. Purposive sampling methods were used because the hub has completed the Woreda level vaccine transition and have better experience on vaccine management. Moreover, all staffs who directly engage on vaccine management were a respondent in this study. For the analysis of the quantitative data descriptive statistics supported by SPSS software version 20 was applied, and for qualitative data document analysis was done.

Result: the study result shows that, the branch has sufficient positive storage capacity, but the available negative storage volume only covers $65 \%$ of negative storage capacity needed. Respondents were agreed on bundling practice during distribution of vaccines, Disagree on Refrigerated vehicle pre cold before loading of vaccines, whereas strongly disagree on temperature of vaccine is always monitored during transportation and availability of adequate number of vehicle for transportation of vaccines for which respondents remained neutral. The investigator has observed as continuous temperature loggers that track and record cold room, refrigerator and freezer temperature were not available to any of the storage facilities and the there is no complete set of temperature records.

Conclusion: The study strongly indicates the need to improve vaccine logistics supply chain management practices, especially in the area of vaccine storage and handling and temperature monitoring. EPSA and development partners working on vaccine logistic and supply chain management should have intensify their technical and material support to improve the vaccine management practices.

\section{Background}

Immunization helps save lives, protects serious illness and is recognized as one of the most effective public health intercessions and available today. However, the success of the programs depends heavily up on the immunization supply chain management including storage, transportation and handling of vaccines in a proper manner (Steele, 2014)

Strong health supply chains are central to achieving positive health outcomes. They deliver the medicines, vaccines, and other supplies needed to save lives, prevent disease, and empower people to live healthy lives (WHO, 2018). Immunization supply chains (iSC) form a unique distribution channel due to their dependence on a well-functioning end-to-end cold chain necessary for ensuring vaccine potency to the last mile, and ultimately to every person being immunized (WHO, 2015). Vaccine storage, transport, and handling are therefore more challenging than most other pharmaceutical products (Anonymous 
2013). Immunization supply chains require supply chain workers to have specialized knowledge and competencies. They require storage facilities to have cold rooms or refrigerators and the power supply and technicians to keep them running. They require transport vehicles that are either refrigerated or able to protect cold boxes from heat extremes. And they require information systems able to track vaccinespecific data, such as vaccine vial monitor (VVM) status, or cold chain equipment (CCE) temperature excursion (CDC, 2015, CDC 2014).

Vaccine cold chain failure occurs when there is a break in any link of the chain. Cold chain failure may occur due to a power failure, staff error, equipment failure, etc. Preventing vaccine cold chain failure requires: properly functioning equipment, appropriately trained staff, clearly written procedures, and easily accessible emergency operating protocols (Anonymous, n.d.).

According to CDC's report, the immunization supply chain and logistic (ISCL) and system, was designed in the 1980. Starting from its inception, it has supported the achievement of acceptable vaccination coverage, using coping mechanisms to overcome enduing challenges in vaccine storage, distribution and management (WHO, 2014). A strong vaccine supply chain that improves to immunization in all global alliance for vaccine initiatives (GAVI) eligible countries like Ethiopia, take good ISCL as a backbone for its mission to be achieved (Steele, 2014). In order to provide an adequate supply of effective vaccine to support the immunization program, measure need to be in place to ensure the vaccine are maintained at peak efficiency, ensure they are free from bad shipment and storage. The temperature should be safe as per the standard at all point of the supply chain (from the manufacturer up to the last mile, the service delivery point. Nevertheless, failure to adhere the proper cold chain requirements will reduce vaccine potency, poor protection and even risk on the child health. CDC says "It is better to not vaccinate than to administer vaccine that has been mishandled" (CDC, 2019).

According to WHO's report, introduction of new vaccine to African countries has also increased storage requirement escalating the existing storage problem (WHO, 2014).

Regarding personnel's engagement on the immunization supply chain logistics in all GAVI eligible Countries, generally untrained health workers are performing the task of (Steele, 2014).

According to the WHO's 2011 report, 50 percent of GAVI eligible countries reported a vaccine wastage rate in excess of WHO's recommendation and 20 percent states of Nigeria had experienced vaccine stock out. In this same report, around 2.8 million vaccine doses are lost in five countries due to cold chain failure and less than 10 percent of countries meet WHO recommendation for effective vaccine management practices. The report also dictates 5 percent of GAVI eligible countries are underperforming on ISCL and less than 25 percent of countries are operating at even a minimum standard on the criteria of maintenance, stock management and distribution. Furthermore, only 29 percent of the countries meet a minimum standard for temperature control (WHO, 2014). Vaccine wastage assessment done in India shows, wastage of all level of the supply chain for a six-month period reflects that maximum wastage occur at the session Site (BCG vaccine has the maximum wastage of 61 percent (UNICEF, 2010). 
A case study done in Nairobi's cold chain supply logistics on the safety of vaccine shows up to 52 percent of respondents conformed there was poor validation and qualification of storage facility and monitoring device. There was no different storage equipment for different vaccine up to 41 percent of the organizations and hence run a risk of cross contamination and temperature excursions during storage which has compromised the quality of vaccine. The research confirmed that validate systems with respect to calibration of storage facility temperature probes and sensors and thermometer were generally poor along the supply chain with only 34 percent having satisfactory practice (Monicah etal., 2015).

In lower income countries of Africa, efforts to implement an efficient cold chain supply process are often hampered by poor health delivery systems. Low political commitment, low levels of investment, poorly maintained cold chain, lack of human resource, poor disease surveillance and reporting systems which are key components of the logistics process are some of the bottleneck observed in the system (Monicah etal. 2015).

According to WHO's 2012 report the average inventory holding point of Ethiopia, which is conducted at five supply chain level, was speculated to increase the wastage rate (WHO, 2012). WHO reported that in Ethiopia 30 percent of cold chain equipment are nonfunctional due to lack of maintenance (WHO, 2014).

Ethiopia, together with the global community launched EPI program since 1980's with six traditional antigens. In order to adopt an end to end supply chain of this program, the Ethiopian Federal Ministry of healthy envisioned the need for proper supply chain of vaccine together with the inception of pharmaceutical logistics master plan (PLMP) in 2007 (EFMOH,2013). To improve vaccine management and distribution system, in 2014, federal minister of health agreed to begin the formal transfer of responsibility for management of vaccine and cold chain along with other health commodities to the Ethiopian pharmaceutical supply Agency (EPSA) (PFSA, 2014) where the transition from existing management system was conducted in a phase based approach. For first phase of the transition, Mekelle, Bahir Dar and Jimma EPSA Hubs are selected. Commencing vaccine distribution from these Phase I Hubs to Zones require forecasting of vaccine requirement for the catchment areas the hubs serve, submission of those forecasts using Vaccine Request Forms (VRF) to EPSA Central/FMOH EPI team, and delivery of vaccines from EPSA Central to the hubs, as per their requests. On top of this, EPSA Jimma was capacitated with refrigerated vehicles and simplified the distribution system from the complex former vertical system which was center- region-zone- Woreda-facility to a far simpler and short cut of only three and four tier system; EPSA center- EPSA hub -Woreda/health facility (PFSA, 2017).

In line with this, the existing health commodity management and information system (HCMIS) software which EPSA was using it for managing the information system for pharmaceuticals, become one of the important tool for managing the information system and inventory control of vaccines.

\section{General Objective}

To assess the immunization supply chain and logistics practice at EPSA Jimma branch 


\section{Specific Objectives}

To assess the storage practice of vaccines at EPSA Jimma

To evaluate the positive and negative temperature storage capacity at EPSA Jimma

To review the transportation means and adequacy of fleet for distribution

To assess the knowledge and skill of staffs engaged on immunization supply chain management practice.

To assess the temperature monitoring practice during storage and transportation of vaccines from center to hub and from hub to Woreda/health facility

\section{Methods}

Institution-based cross sectional study design was conducted to assess and describe the nature; condition and degree of the present situation of immunization supply chain practice of the agency, mainly the storage and distribution of vaccines. A descriptive design is ideal for studies that will be carried out in a limited geographical scope and hence is logistically easier and simpler to conduct considering the limitations of this study (Kothari, 2004). The study was conducted from September to October 2019 in Ethiopian pharmaceuticals supply agency (EPSA) Jimma branch. EPSA Jimma branch is located $554 \mathrm{~km}$ away from Addis Ababa in south western part of Ethiopia with responsibility to serve public and private health facilities found in south western part of Ethiopia. The study populations were staffs involved on immunization supply chain management; these are the stock and distribution officers, vaccine focal person, cold room managers, refrigerated truck drivers, vaccine delivery personnel and the CCE maintenance technician.

Purposive sampling methods were used because the hub has completed the Woreda level vaccine transition and have better experience on vaccine management. Moreover, all staffs who directly engage on vaccine management were a respondent in this study. The primary data was collected by using structured questionnaires and Standard check list observation. In addition, secondary data was collected from documents and recordings from the manual and electronic recording tools. Qualitative and quantitative data was collected and analyzed according to its type. For the analysis of the quantitative data descriptive statistics supported by SPSS software version 20 was applied, and for qualitative data document analysis was done. SPSS mean and standard deviation was used to calculate and show the experts experience on immunization supply chain practices, and frequency and percentage were considered to present the respective practices

\section{Results}


The general characteristics of the respondent gives the clue that respondents have the necessary understanding and knowledge about subject matter and understand the objective of the study to respond each item in questionnaire.

Table 1: Demographic characteristics of respondents of the study

\begin{tabular}{|l|c|c|}
\hline Variables & Frequency & Percentage (\%) \\
\hline Gender of the respondents \\
\hline Male & 5 & 71.4 \\
\hline Female & 2 & 28.6 \\
\hline Age of the respondents \\
\hline $18-25$ & 1 & 14.3 \\
\hline $26-35$ & 6 & 85.7 \\
\hline Educational background of the respondent \\
\hline College Diploma & 4 & 57.1 \\
\hline Bachelor's Degree & 2 & 28.6 \\
\hline Postgraduate & 1 & 14.3 \\
\hline Respondents years of experience in the agency \\
\hline 1-5 & 4 & 57.1 \\
\hline 6-10 years & 2 & 28.6 \\
\hline More than 10 years & 1 & 14.3 \\
\hline
\end{tabular}

Source: Survey data (2019)

The general demographic characteristics (age, gender, educational background and year of experience) of the respondents of the study were presented by using frequency statistics in table 1, among 7 respondents $71.4 \%$ (5) and $28.6 \%$ (2) were male and female respectively. With regard to age of the respondents $14.3 \%(1)$ and $85.7 \%(6)$, of the respondents were in the age category of 18 to 25 old, and 26 to 35 old respectively. Concerning educational level $57.1 \%(4), 28.6 \%(2)$, and $14.3 \%$ (1) were College Diploma, Bachelor's Degree and Postgraduate respectively. The respondent's experience in the job were found to be 1 to $5,6-10$ and more than 10 years for $57.1 \%(4), 28.6 \%(2)$, and $14.3 \%(1)$ of the respondents' respectively with most of them spent 1-5 years in EPSA Jimma.

Description of vaccine storage practice: Respondents were asked to rate the vaccine storage practice on a five point Likert scale (strongly disagree, disagree, neutral, agree and strongly agree). The mean was computed and utilized with the following assumption: if the mean value is between 0 to 1.5 this implies the respondents strongly disagreed, if the mean value is between 1.5 to 2.5 it implies the respondents' disagreed, if the mean value is between 2.5 to 3.5 it implies the respondents were neutral, if the mean value between 2.5 to 3.5 it implies the respondents were neutral, if the mean value between 3.5 to 4.5 implies the respondents' agreed and a mean value 4.5 and above indicates the respondents' strongly agreed 
The adequacy of storage capacity, responses computed for mean and standard deviation. The respondents remained neutral on availability of temperature monitoring device in the cold/freezer room (mean=3.00, SD $=1.00$ ), disagree on availability of adequate negative storage space for vaccines (mean $2.00, S D=0.00$ ) and backup generator in case of power outage (mean=2.33 and, $S D=0.577$ ). But they agreed on Daily temperature monitoring practice is in place (mean $=4.00, S D=0.00)$, contingency plan in case of cold room failure (mean $=4.33, S D=0.577$ ), and Safety warehouse clothing is in place (mean $=4$, $S D=0.00)$ and the respondents were strongly agreed for adequacy of positive storage space for vaccines (mean $=4.66, S D=0.577$ ) as shown in table 2 . A document review shows that 265,568 births infant, 246,435 surviving infants, were rendering services from the hub, and there is $90 \mathrm{~m} 3$ gross volume of positive storage ( +2 to +8 degree Celsius), accordingly to WHO recommendation the available storage space is adequate.

Table 2: The mean and standard deviation values for adequacy Vaccine storage

\begin{tabular}{|l|c|c|c|}
\hline Statement & N & Mean & $\begin{array}{c}\text { Std. } \\
\text { Deviation }\end{array}$ \\
\hline There is adequate positive storage space for vaccines & 3 & 4.6667 & .57735 \\
\hline There is adequate negative storage space for vaccines & 3 & 2.0000 & 0.00000 \\
\hline There is temperature monitoring device in the cold/freezer room & 3 & 3.0000 & 1.00000 \\
\hline $\begin{array}{l}\text { Daily temperature monitoring practice is in place (temperature } \\
\text { recorded twice daily) }\end{array}$ & 3 & 4.0000 & 0.00000 \\
\hline There is backup generator in case of power outage & 3 & 2.3333 & .57735 \\
\hline There is contingency plan in case of cold room failure & 3 & 4.3333 & .57735 \\
\hline $\begin{array}{l}\text { There is proper CCE maintenance structure for corrective and } \\
\text { preventive maintenance }\end{array}$ & 3 & 3.6667 & .57735 \\
\hline Safety warehouse clothing is in place & 3 & 4.0000 & 0.00000 \\
\hline
\end{tabular}

Source: Survey data (2019)

Distribution and Transportation of Vaccines: Respondents agreed on bundling practice during distribution of vaccines (mean $=3.8571, S D=0.69007$ ), Disagree on Refrigerated vehicle pre cold before loading of vaccines (mean $=2.0000, S D=0.81650$ ), whereas strongly disagree on temperature of vaccine is always monitored during transportation (mean $=1.1429, S D=0.37796$ ) and availability of adequate number of vehicle for transportation of vaccines (mean=3.1429, $S D=1.34519)$ for which respondents remained neutral as shown in table 3.

Table 3; the mean and standard deviation from survey data-distribution and transportation of vaccines 


\begin{tabular}{|l|c|c|c|}
\hline Statement & N & Mean & $\begin{array}{c}\text { Std. } \\
\text { Deviation }\end{array}$ \\
\hline $\begin{array}{l}\text { There is adequate number of vehicle for transportation of } \\
\text { vaccines }\end{array}$ & 7 & 3.1429 & 1.34519 \\
\hline Refrigerated vehicle pre cold before loading of vaccines & 7 & 2.0000 & .81650 \\
\hline $\begin{array}{l}\text { The temperature of vaccine is always monitored during } \\
\text { transportation }\end{array}$ & 7 & 1.1429 & .37796 \\
\hline $\begin{array}{l}\text { There is bundling practice during distribution of vaccines } \\
\text { (integrating vaccine with its consumables) }\end{array}$ & 7 & 3.8571 & .69007 \\
\hline
\end{tabular}

Knowledge of staff on vaccine management: Respondents were asked question for the recommended temperature range for most vaccine stored and transported in degree Celsius and results are summarized in figure 1. Majority $(71.4 \%)$ of respondents had knowledge on recommended temperature range for most vaccines stored and transported and $(28.6 \%)$ of the respondents had no knowledge on recommended temperature range for vaccines stored and transported.

Insert Figure 1 here

\section{Knowledge of Respondents on Sensitivity of Vaccines to Freeze and Light, Shake Test, Vaccine Vial Monitor (VVM), WHO MDV Policy and Conditioning Ice Pack.}

Table 4:- Knowledge of Respondents on Sensitivity of Vaccines to Freeze and Light, Shake Test, Vaccine Vial Monitor (VVM), WHO MDV Policy and Conditioning Ice Pack.

\begin{tabular}{|l|c|c|}
\hline \multicolumn{1}{|c|}{ Statement } & Frequency & Percentage (\%) \\
\hline Knows highly freeze sensitive vaccine & 4 & 57 \\
\hline Knows Vaccine highly sensitive for light? & 3 & 43 \\
\hline Knows the vaccine to be stored in freezer room & 5 & 71 \\
\hline Knows about shake test & 2 & 29 \\
\hline Knows about Vaccine Vial Monitor (VVM) & 6 & 86 \\
\hline Knows WHO multi dose vial policy & 1 & 14 \\
\hline Knows conditioning of ice pack & 5 & 71 \\
\hline
\end{tabular}

Majority 6 (86\%) knew the correct definition for Vaccine Vial Monitor (VVM), 5 (71\%) knew the vaccine to be stored in freezer room and conditioning of ice pack. The knowledge of shake test and WHO multi dose vial policy was poor among a higher proportion of respondents, $5(71 \%)$ and $6(84 \%)$, respectively. Just over half of the respondents $4(57 \%)$ had poor knowledge of freeze sensitive vaccines. Respondents trained on vaccine management had better knowledge of vaccine vial monitor (VVM) 6 (86\%), 5 (71\%) knew conditioning of ice pack and $5(71 \%)$ knew the vaccine to be stored in freezer room than untrained staffs as shown in table 4. 
Regarding Training status of Respondents on different areas of vaccine management, on average $70 \%$ of employee had on service training and all respondents were trained on VVM reading (100\%) as shown in table 5.

Table 5:- Training status of Respondents on different areas of vaccine management

\begin{tabular}{|l|c|c|}
\hline \multicolumn{1}{|c|}{ Training on } & Frequency & $\begin{array}{c}\text { Percentage } \\
\text { (\%) }\end{array}$ \\
\hline Correct storage temperatures; & 6 & $86 \%$ \\
\hline Vaccines damaged by freezing; & 3 & $43 \%$ \\
\hline Vaccines which can be frozen & 4 & $57 \%$ \\
\hline Vaccines which must be frozen; & 4 & $57 \%$ \\
\hline VVM reading & 2 & $100 \%$ \\
\hline Shake test & 6 & $29 \%$ \\
\hline Temperature monitoring using the range of available devices & & $86 \%$ \\
\hline Storage of diluents & 5 & $71 \%$ \\
\hline $\begin{array}{l}\text { How to arrange vaccines in cold rooms, freezer rooms, } \\
\text { refrigerators and freezers }\end{array}$ & 6 & $86 \%$ \\
\hline Icepack conditioning & 5 & $71 \%$ \\
\hline Cold box/vaccine carrier packing & 6 & $86 \%$ \\
\hline
\end{tabular}

Vaccines storage and handling practice: From one to one interview and document review, the investigator has observed as continuous temperature loggers that track and record cold room, refrigerator and freezer temperature were not available to any of the storage facilities and the there is no complete set of temperature record. Temperature-sensitive alarms that alert the cold chain officer via SMS during prolonged exposure to out-of-range temperatures were also not available at the storage areas.

Temperature mapping and devices calibration was not done for all cold rooms, freezers and refrigerators. The correct number and placement of ice packs inside the cooler is important because too few ice packs can fail to maintain the internal cooler temperature and too many ice packs have the potential to freeze the vaccine and in this facility it is found to be sufficient storage capacity fore icepacks.

A written contingency plan in case of equipment failure, natural disaster, or major power outage should be available. The contingency plan, prepared well in advance, should be prominently located, be freely accessible, and include: Contact information for the relevant stakes, their role and the elements or conditions. In the study area there was well organized contingency plan was in place.

\section{Discussion}

The result above showed that there are rooms for improvement in order to ensure recommended good storage. Although respondents agree on all items with some variables like availability of storage 
equipment for different vaccine, contingency plan development and implementation of SOP are relatively on lower scale in this range. Control of storage conditions and temperature is essential in maintaining the quality of cold chain items and in helping to protect patients from sub-standard or ineffective medicines that may result from inadequate storage control (CDC, 2014). For measuring vaccine storage unit temperatures, $\mathrm{CDC}$ recommends using only calibrated temperature monitoring devices with a Certificate of Traceability and Calibration Testing (also known as Report of Calibration). Calibration testing should be performed every 1 to 2 years or according to manufacturer's suggested timeline. Temperature mapping should be done for all storage areas (CDC, 2014).

Vaccines need specialized storage because of the very sensitive nature of these biological products. As a result, the type of equipment used for storing vaccines needs to be specialized according to different temperature zones, and the service level of storage. Storage capacity needs to be sufficient to meet the immunization needs, and transport containers must keep the vaccines in optimal condition throughout the journey. The study was concerned about one aspect of cold storage whether or not the existing storage capacity is adequate to accommodate all vaccines ( 4 months stock with $25 \%$ buffer stock in relation to its target population) need. This assessment, therefore, tried to calculate the storage capacity based target population, birth infant $(265,568)$ and surviving infant $(246,435)$ for all available cold stores (Cold rooms, refrigerators and freezers) and compared with WHO recommended storage capacity needed and the branch has sufficient positive $\left(+2^{0 \mathrm{C}}\right.$ to $\left.+8^{0 \mathrm{C}}\right)$ storage capacity, but the available negative storage volume only covers $65 \%$ of negative storage capacity needed (WHO, 2014).

Immunization supply chains require supply chain workers to have specialized knowledge and competencies. They require storage facilities to have cold rooms or refrigerators and the power supply and technicians to keep them running. They require transport vehicles that are either refrigerated or able to protect cold boxes from heat extremes. And they require information systems able to track vaccinespecific data, such as vaccine vial monitor (VVM) status, or cold chain equipment (CCE) temperature excursion (UNOPS, n.d). The distribution system of vaccines is concerning with maintaining of the cold chain. The cold chain is the system of transporting and storing of vaccine at the recommended temperature range which is $\left(+2{ }^{\circ} \mathrm{C}\right.$ to $+8^{\circ} \mathrm{C}$ for refrigerator vaccines) and $\left(-15^{\circ} \mathrm{C}\right.$ to $-25^{\circ} \mathrm{C}$ for freezer vaccines).

In this study respondents agreed on bundling practice during distribution of vaccines, Disagree on Refrigerated vehicle pre cold before loading of vaccines, whereas strongly disagree on temperature of vaccine is always monitored during transportation and availability of adequate number of vehicle for transportation of vaccines for which respondents remained neutral. Similar study conducted in coast region, Tanzania showed that the main cause of delay in delivery of vaccines to the health centers was shortage or lack of transport to distribute the vaccine. As indicated in similar study lack of reliable transport at district level contributes to shortage of vaccines at health facility level (Makuru M., 2012).

To maintain vaccines perfectly conserved from its manufacture through administration requires an adequate cold chain infrastructure, compliance to standards and effective management. At the end of the 
chain staffs that managing the vaccines must have adequate knowledge to manage the cold chain. To improve management, the World Health Organization (WHO) has created a set of practice guidelines for different service levels, which include immunization techniques, vaccine monitoring, cold chain management and reporting systems (WHO, 2014). The study was tried to asses the Knowledge of respondents on vaccine management on each routine vaccine, appropriate storage conditions (temperature range), stages of changes in Vaccine vial monitors (VVM) and actions to be taken on vials with changed VVM, shake test, WHO MDV and ice pack conditioning. Majority respondents knew the correct definition for vaccine vial monitor (VVM), the vaccine to be stored in freezer room and conditioning of ice pack. The knowledge of shake test, and WHO multi dose vial policies was poor among a higher proportion of respondents.

All personnel who handle deliver or receive vaccine shipments and anyone who has access to the unit(s) where vaccines are stored need to have the proper knowledge on vaccines. Vaccine storage and handling training should be provided to all new personnel who handle or administer vaccines, including temporary staff. Continuing education for staff is essential when new vaccines are stocked and when there are any changes to the storage and handling guidelines for a particular vaccine. It is mandatory to familiarize the storage and handling of vaccines for all institutions engaged on immunization supply chain activities (GAVI, 2014).

Temperature Monitoring is a critical part of good storage and handling practice and it is necessary to undergo periodic calibration testing. Testing should be performed every 1 to 2 years from the last testing date or according to the manufacturer's suggested timeline. CDC recommends that testing meets standards defined in the Vaccine Storage and Handling Toolkit. If calibration testing indicates that the temperature monitoring device is no longer accurate, it should be replaced (CDC, 2014). All vaccines and their diluents must be stored and distributed within a cold-chain system that maintains, at all times, the WHO-recommended temperatures ranges for all types of vaccines (WHO, 2014). In study area there is no systematic temperature monitoring, a complete set of manual temperature records/ temperature logger printouts for each and every cold room, refrigerated vehicle, vaccine refrigerator and vaccine freezer and there temperature records formally reviewed at least once a month in order to identify temperature excursions and their causes and temperature mapping and a test calibration were not done for all devices.

\section{Conclusion}

The study strongly indicates the need to improve vaccine logistics supply chain management practices, especially in the area of vaccine storage and handling and temperature monitoring. EPSA and development partners working on vaccine logistic and supply chain management should have intensify their technical and material support to improve the vaccine management practices. In study area there is no systematic temperature monitoring, a complete set of manual temperature records/ temperature logger printouts for each and every cold room, refrigerated vehicle, vaccine refrigerator and vaccine freezer and there temperature records formally reviewed at least once a month in order to identify 
temperature excursions and their causes and temperature mapping and a test calibration were not done for all devices. This study just focused on logistics and supply chain management practices in the case of EPSA Jimma, further research can be carried out to cover the all EPSA branches to assess the magnitude of the problem.

\section{Limitations of the study}

This study focuses on the immunization supply chain practice mainly the storage, handling and transportation of vaccines from center to hub and from hubs to service delivery level (Woreda and health facilities). Therefore, as the study area is limited to Jimma hub, it will have limitation on representativeness of the agency as a whole.

\section{Recommendations}

- EPSA and development partners should have to work more to improve storage practices, by providing on job training/class room training, continuing supportive supervision, by Temperature mapping and calibrating cold rooms, freezers and refrigerators

- EPSA and development partners working in immunization logistics and supply chain management should invest more on negative cold store devices.

- EPSA need to strengthen the transport system of cold chain vaccines according to their optimum temperature ranges, because the temperature may affect their quality.

- EPSA - Need to supply freezer tags to all cold chain warehouses which can help in monitoring and recording temperature even when the store managers in charge were absent.

- There must be a systematic temperature monitoring study been carried out for the cold rooms.

- There must be a complete set of manual temperature records for each and every cold room, freezer room, vaccine refrigerator and vaccine freezer.

- There must be a complete set of temperature recorder traces and/or temperature logger printouts for each and every refrigerated vehicle.

- Temperature records should be formally reviewed at least once a month in order to identify temperature excursions and their causes.

\section{Abbreviations}

BCG:Bacille Calmette Guerin; CDC:Center for Disease Prevention and Control; EPI:Expanded Program for Immunizations; GAVI:Global Alliance for Vaccine and Immunizations; HCMIS:Health Commodity Management Information System; ISCL:Immunizations Supply Chain Logistics System; ISCM:Immunization Supply chain Management; EFMOH:Ethiopian Federal Ministry Health; EPSA:Ethiopian Pharmaceutical Supply Agency; PLMP:Pharmaceutical Logistics Master Plan; UNICEF:United Nations Children's Fund; UNOPS; United Nation Office for Project Service; WHO:World Health Organization; VVM:Vaccine Vial Monitor. 


\section{Declarations}

\section{Ethics approval and consent to participate}

Ethical clearance was obtained from the Research and Ethical Committee of Leadstar University Collage cooperates with Ashland University/Ohio/USA. Informed consent was obtained in written form, and all participants agreed to participate in the study.

\section{Consent for publication}

Not applicable

\section{Availability of data and materials:}

The dataset collected and analyzed for the current study is available from corresponding author and can be obtained on a reasonable request.

\section{Competing interests}

The author declares that they have no competing interests.

\section{Funding}

The authors did not receive any funding for this study.

\section{Author's contributions}

TAW has initiated the idea, wrote the proposal, select the study design, methods, collect data, analyze, interpret and produce this manuscript

\section{Acknowledgments:}

I would like to thank all people who directly or in directly helped me in this work. Lastly, I would like to thank EPSA Jimma staffs for their unreserved cooperation and support for all over data collection process

\section{Author's Information}

Name: Mr. Tekalign Admasu Weledesenbet (B. Pharm, MBA)

Current position; Capacity Building and operational research officer at Ethiopian pharmaceuticals Supply Agency

Email; - tekepharm@gmail.com

Phone; - +251910052366 


\section{References}

1. Anonymous. 2013. Storage, distribution and disposal of vaccines, Green Book Chapter 3 v2_1.

2. Anonymous. n.d. Vaccine Storage and Handling Guidelines. Ontario, Canada.

3. C.R. Kothari. 2004. Research Methodology, Methods and Techniques second revised edition.

4. CDC, "Vaccine storage and handling toolkit," 2019.

5. CDC (Center for Disease Control and Prevention). 2014. Vaccine Storage\& Handling Toolkit.

6. CDC (Centers for Disease Control and Prevention). 2015. Storage and Handling, Epidemiology and Prevention of Vaccine-Preventable Diseases, 13th Edition.

7. EFMOH (Ethiopian Federal Ministry of Health). 2013. Effective Vaccine Management Assessment, towards improving the immunization supply chain management.

8. GAVI (Global Alliance for Vaccine Initiatives). 2014. The Vaccine alliance immunization strategy.

9. Makuru, M. (2012). ASSESSIMENT OF VACCINES DISTRIBUTION SYSTEM IN PUBLIC HEALTHCARE FACILITIES IN COAST REGION , A dissertation / Thesis submitted in ( partial ) Fulfillment of the Requirements for the Degree of Master of Science (Pharmaceutical Management) of Muhimbili University of Health and Allied Sciences Muhimbili University of Health and Allied Sciences October, 2012.

10. Steele, P. 2014. GAVI Supply Chain Strategy People and Practices Evidence Review.

11. Monicah W., Dr. Christopher J. and Dr. Kepha 0.2015. Influence of Cold Chain Supply Logistics on the Safety of Vaccines. A Case of Pharmaceutical Distributors in Nairobi County.

12. PFSA (Ethiopian Pharmaceuticals fund and Supply Agency). 2014. Vaccine supply chain and logistics transition plan.

13. PFSA (Ethiopian Pharmaceuticals fund and Supply Agency).2017. Pharmaceutical Supply Process Reengineering for Pharmaceuticals Fund and Supply agency.

14. UNICEF (United Nation Children`s Fund). 2010. Vaccine Wastage Assessment. Field assessment and observations from National stores and five selected states of India.

15. UNOPS (United Nation Office for Project Service) .n.d. Vaccine and Logistics management Health Managers Modules for Immunization

16. WHO (World Health Organization) 2018. Delivering quality health services: a global imperative for universal health coverage.

17. WHO (World Health Organization). 2012. Health Canada Drafting Group Meeting on Scientific and Regulatory Considerations on the Stability Evaluation of Vaccines under Controlled Temperature Chain. Ottawa, Canada.

18. WHO (World Health Organization). 2014. A CALL-TO-ACTION for national program and the global community by the WHO immunization practices advisory committee. GENEVA, SWITZERLAND.

19. WHO (World Health Organization). 2014. Assessment report of the global vaccine action plan strategic advisory group of experts on immunization. 
20. World Health Organization (WHO), Immunization in Practice: A Practical Guide for Health Staff, World Health Organization, Switzerland, 2015.

\section{Supplementary Files Legend}

Additional file 1 Questionnaire of this study

\section{Figures}

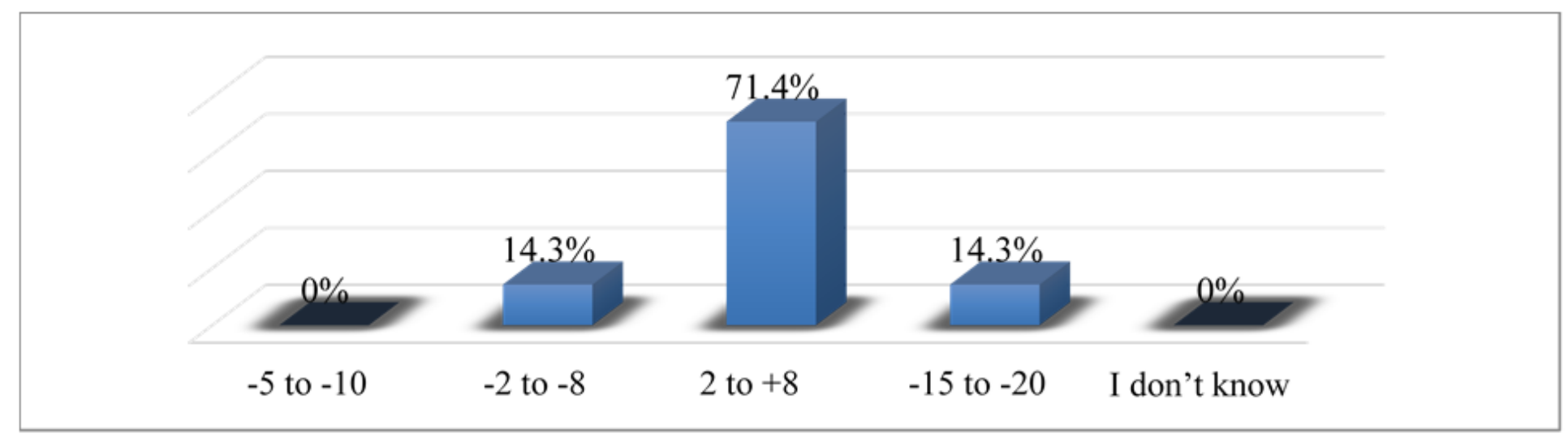

Figure 1

Knowledge level of respondents on recommended temperature range for most vaccines stored and transported in degree Celsius.

\section{Supplementary Files}

This is a list of supplementary files associated with this preprint. Click to download.

- Questionerofthestudy.docx

- STROBEchecklistTekalignAdmasul.doc 